\title{
Diplomacia en torno a La obra de Trajano: un discurso y un artículo desconocidos de Ramón de Basterra sobre Rumanía
}

\author{
Mariano MARTÍN RODRÍGUEZ \\ martioa@yahoo.com
}

\begin{abstract}
RESUMEN
Como secretario de la Legación española en Rumania, el poeta y ensayista novecentista Ramón de Basterra desempeñó una intensa labor diplomática, tal como se desprende de sus despachos diplomáticos. Su estancia en Rumania también le inspiró a uno de los mejores libros que haya escrito nunca un extranjero sobre la nueva gran nación latina, La obra de Trajano (1921). Sus ideas impregnan también otros dos textos suyos desconocidos, los cuales constituyen asimismo buenas muestras de la prosa muy culta de Basterra: su discurso como representante español en la ceremonia de inauguración de la Universidad rumana de Cluj y el último artículo que escribió, el cual vio la luz póstumo en una revista hispanorrumana de Bucarest. Ambos textos se recuperan en este trabajo.
\end{abstract}

Palabras clave: Basterra, Rumanía, testimonio histórico, La obra de Trajano, textos desconocidos

[Recibido, julio 2010; aprobado, diciembre 2010]

Diplomacy on Trajan's Work: a speech and an unknown article

by Ramón de Basterra about Romania

\begin{abstract}
As the secretary at the Spanish Embassy in Romania, the modernist poet and essayist Ramón de Basterra displayed an outstanding diplomatic activity, as his reports to his superiors show. His stay in Romania also inspired him one of the best books ever written by a foreigner on this great new Latin nation, which he entitled Trajan's Work (La obra de Trajano, 1921). His ideas also permeate two other unknown texts by Basterra, which are also good examples of his highly literate prose: his speech as the Spanish representative at the opening ceremony of the Romanian University in Cluj and the last article he wrote, which was published shortly after his death in a Spanish-Romanian journal from Bucharest. Both texts are reproduced in this essay.
\end{abstract}

Keywords: Basterra, Romania, historical testimony, Trajan's Work, unknown texts

Aunque no se trate de uno de los escritores más famosos de una generación que, en España, cuenta con figuras de talla tal como José Ortega y Gasset o Juan Ramón Jiménez, Ramón de Basterra tampoco ha sido olvidado. Así, se le han dedicado diversos estudios críticos, libros incluso ${ }^{1}$, y sus poesías completas han sido

\footnotetext{
${ }^{1}$ La bibliografía que se le ha dedicado es relativamente amplia. Las entradas que figuran en un ensayo (Larrabide 2002) sobre las distintas ediciones de sus textos y los estudios que se le han dedicado ocupan ahí un buen número de páginas (142-174), aun faltando todas las contribuciones rumanas, desde las de Nicolae Iorga.
} 
objeto de una edición de gran calidad gráfica y científica en una colección dedicada a los escritores modernos españoles que, en el contexto brillante de la llamada Edad de Plata española, habían visto algo eclipsada su obra por la calidad insigne de los ingenios de primera fila en los dos géneros principales cultivados por Basterra, la lírica y el ensayo. Sin embargo, su olvido relativo no nos debe hacer perder de vista el papel que desempeñó en la cultura española, pese a todos los equívocos ideológicos de que ha sido y sigue siendo víctima como representante del ala conservadora de su grupo generacional. La instrumentalización de algunas de sus ideas por parte de la intelectualidad del régimen del general Francisco Franco ${ }^{2}$ no es ajena a su consideración, todavía frecuente en un panorama cultural fuertemente polarizado, como autor fascista $^{3}$, pese a que su fallecimiento en 1928 es anterior a

\footnotetext{
${ }^{2}$ Un investigador (Amat 2004) se ha ocupado con todo detalle de la reivindicación de la figura de Basterra por parte de un historiador de la literatura prestigioso, Guillermo Díaz-Plaja, el cual habría intentado así ganar las simpatías de los vencedores de la Guerra Civil española (él había luchado en el otro bando) y asegurar su posición en el mundillo cultural de los primeros años, los más duros, del régimen franquista. La operación presentaba para él ventajas indudables: por una parte, Basterra era un escritor conservador, pero no reaccionario, y es de imaginar que chocara menos con las ideas de Díaz-Plaja, más bien liberales en su contexto; por otra parte, su estudio (Díaz Plaja 1941) podía aprovechar, reorientándola en un sentido más aceptable, la tendencia de la Falange (esto es, los fascistas o legionarios españoles) a apropiarse de su obra «para sustentar su discurso ideológico», porque «ante el esquematismo sustento ideológico sobre el que se construía el discurso falangista, el tradicionalismo explícito en los versos de Bastera -la recurrente mitificación de Roma como cumbre de Occidente, la fascinación por la idea de imperio- facilitaba contenidos posibles para una forma de comprensión del mundo que carecía de fundamentos sólidos» (Amat 2004: 11), aunque fuera a costa de silenciar lo mucho que se oponía en Basterra a los tópicos del régimen (sobre todo su defensa de la tradición ilustrada y su internacionalización mental opuesta a toda idea de autarquía). La tentantiva de Díaz-Plaja fue bastante mal acogida por los círculos falangistas más exaltados, puesto que su libro, de alta calidad científica por lo demás, mereció una reseña asesina en la principal revista de aquéllos, Escorial. Díaz-Plaja no dejó por ello de ocuparse de nuestro autor, como prueba de que su interés no era puramente circunstancial, y le dedicó otros artículos, además de editar varios de sus textos desconocidos (Díaz-Plaja 1970), entre otros la conferencia pronunciada por Basterra en Sevilla sobre la obra de Trajano. Con posterioridad a su monografía apareció otra, de aire más científico (era una tesis doctoral), también en estos años (Areán González 1953), tras la cual la figura de Basterra sufrió un largo eclipse, hasta su recuperación paradójica como precursor de la literatura fascista española por parte de los estudiosos de izquierda. Gracias a ellos, los falangistas consiguieron finalmente su propósito de apropiárselo. El resultado de esta visión deformada son errores de bulto hasta en investigaciones serias, cuando se cae en los tópicos en vez de atender a los documentos. Por ejemplo, se puede leer algo así como «En Rumania, destino diplomático de Basterra entre 1917 y 1920, el autor entra en contacto con el fascismo emergente de ese país» (Ortega 2001: 88), lo que denota suma ignorancia de la historia rumana, donde ese movimiento aparecería mucho más tarde, igual que en el resto de Europa.

${ }^{3}$ José Carlos Mainer es quien más ha glosado la figura de Basterra relacionándola anacrónicamente con el fascismo español (iy hasta con el rumano de la Guardia de Hierro!). La antipatía ideológica que este hecho le produce se trasluce en las páginas más bien injustas, cuando no completamente fuera de lugar desde el punto de vista literario (el único pertinente en un trabajo de estas características), que le dedica en la introducción a sus poesías completas y que lo llevan apriorísticamente a valorar su obra de forma negativa. Así, le dedicó juicios apriorísticos y sin justificar como el siguiente: sobre Rumania «quiso contarlo todo en un libro ambicioso y fallido, como todo lo su-
} 
la aparición de la rama española de la ultraderecha nacionalcorporativista europea. Además, en sus pronunciamientos políticos, nunca en favor de un partido en concreto, resulta difícil distinguir rasgos que lo liguen directamente a las doctrinas o prácticas mussolinianas. No olvidemos que, de izquierdas o de derechas, los extremos políticos entonces en liza invocaban ambos el interés de las masas y se presentaban como fenómenos revolucionarios, cosa que no suscitaba demasiadas adhesiones entre los intelectuales modernos de tendencia reformista, los cuales promovían la guía de las minorías preparadas frente a la rebelión de las masas Así, «si bien no se encuentra en Basterra una abierta crítica a la democracia, si es evidente una ideología elitista que conecta con las ideas dominantes en la época» (Duplá 1996: 95). Es en este contexto concreto donde hay que situar a nuestro autor, cuyo conservadurismo dista de ser reaccionario o, en cualquier caso, se presta a numerosas matizaciones. Es verdad que podía apuntar en este sentido su idealización del imperio latino, especialmente en la figura del emperador Trajano, que lo llevó a su apogeo territorial, pero la Roma de Basterra no era la urbe real e histórica, sino más bien el símbolo de una serie de valores políticos y, sobre todo, morales (disciplina, equilibrio, servicio desinteresado de las minorías rectoras a la sociedad, etc.) que deseaba ver resucitados en su tiempo. No se trataba de un pasado mirado con ojos meramente nostálgicos, sino de un ejemplo al servicio de una modernización basada, por una parte, en un rearme ético que se esforzó por encarnar en su propia vida, aun a costa de su salud mental, y por otra, en una puesta al día social y económica que hiciera volver a España (y a Rumania, las muchas veces que habló de ella) a tener mayor peso en el concierto de las naciones. Esta modernización entrañaba un planteamiento inherentemente progresivo, al menos en términos materiales, lo que no quiere de decir que tuviera que ser progresista: Basterra no lo era ciertamente si nos atenemos a su monarquismo sin falla, a su desconfianza hacia el orden liberal decimonónico y a su anticomunismo, que se afirmó (o reafirmó) durante su estancia en Rumania, al conocer de primera mano la índole expansiva del nuevo régimen soviético, el cual representaba la mayor amenaza que se cernía sobre la Dacia rediviva, como luego acabaría confirmando su anexión por las armas de Besarabia y del norte de Bucovina. De este modo, conservadurismo y ansias de modernización conviven de manera más o menos inestable y conflictivo en su ideario. Pero Basterra era un hombre contradictorio,

yo», antes de condenar «la prosa, que quiere ser florida y resulta pedregosa de La obra de Trajano» (Basterra 2001, I: XXVIII). Uno se pregunta la razón por la que le consagró entonces tanto esfuerzo. Por fortuna, su profesionalidad se impone a menudo y su edición, hecha abstracción de sus prejuicios, tiene el valor filológico que se puede esperar de un erudito como Mainer. Además, no dudó en reconsiderar algunas de sus afirmaciones en un trabajo posterior (Mainer 2003), en que hace hincapié en las contradicciones inherentes al pensamiento basterriano, aunque aún con un desagradable punto de crueldad: «En todo caso, la esquizofrenia es inherente a Ramón de Basterra y quizá su mérito principal y lo que puede rescatarlo de la unilateralidad reaccionaria» (Mainer 2003: 190). 
un «progresista retrógrado»" en lucha constante por llegar a una síntesis hacia la que tendió con mayor o menor éxito, sin llegar a alcanzarla: aunque sus ideas se manifiestan con creciente claridad a lo largo de su evolución, está claro que no llegó a crear un sistema de pensamiento estructurado ${ }^{5}$. Además, si otros escritores asumieron sus paradojas íntimas y hasta las aprovecharon para crear una literatura dialéctica, como su maestro Miguel de Unamuno, Basterra no acertó a satisfacer «el afán de armonizar contrarios» (Ortega Gallarzagoitia 2001: 52). En su idealismo radical, contraponía el placer y el deber, que creía «antagónicos» ya desde su juventud: «o felicidad o cultura», o la vida de burgués o la de escritor, «o la borrachera estruendosa y las juergas ínfimas o las veladas silenciosas persiguiendo un problema abstruso» (Basterra 1989: 72). Su biografía demuestra que se quedó con lo segundo y que ello le exigió una disciplina considerable ${ }^{6}$. Su obsesión por el

${ }^{4}$ Así lo llamó Juan Ramón Jiménez en el texto que dedicó a nuestro autor en su colección de retratos líricos en prosa de 1942 Españoles de tres mundos (Jiménez 1960: 193).

${ }^{5}$ Tal vez su demencia y temprana muerte se lo impidieron: «[...] la muerte le sorprendió después de haber creado una interpretación neo-spengleriana de la Historia, pero antes de haber podido recoger en un nuevo libro doctrinal los atisbos supranacionales y supraculturales que llenaron sus largas horas de meditación durante los años finales de su fructífera vida» (González Areán 1953: 124).

${ }^{6}$ La diplomacia significaba para nuestro autor sobre todo un esfuerzo cultural y político. Sus despachos diplomáticos prueban su excepcional desempeño en el trabajo, hasta el punto de caer enfermo. Los primeros ataques de demencia que lo llevaron al sepulcro en 1928 se produjeron en 1920, cuando estaba destinado en Rumania, y Basterra mismo declaró oficialmente a su Ministerio que había padecido «una larga y penosa enfermedad en razón de las penalidades que, durante de la guerra, hubo de padecer en el Oriente cercano», la cual lo había dejado «incapacitado para el manejo de la pluma y de la mente», según figura en el expediente personal de Ramón de Basterra (citado en Ortega 2001: 17), que se conserva en el archivo del Ministerio de Estado (actual Ministerio de Asuntos exteriores). Además, según el testimonio de las Memorias de Nicolae Iorga, el 13 de mayo de 1920 se sentía muy cansado, tras las penalidades sufridas en la Rumania ocupada y el trabajo tan duro que le había supuesto compaginar su labor diplomática con la escritura personal (poemas y un libro tan complejo como La Obra de Trajano), por lo que el traslado a su segundo destino, Venezuela, se explica también por un deseo de alejarse de las tensiones europeas en un momento en que su salud ya se estaba resintiendo (Iorga 1932: III, 20):

Amicul meu spaniol Basterra veni la mine. E bolnav şi obosit. Şi-a terminat cartea despre România. Vrea să trăiască într-un loc unde n-a fost războiul cu lipsurile şi cu mizeriile lui. Şi-a cerut şi căpătat mutarea.

Al menos su empeño extraordinario fue reconocido tanto por sus superiores, como por la propia Rumania, que le concedió una orden honorífica. El 29 de julio de 1920, G. Crețeanu comunicó al Ministro de Estado de España, Marqués de Lema, que el Rey de Rumania «a daigné conférer à Monsieur Ramon de Basterra y Zabala, ancien Secrétaire près de la Légation d'Espagne à Bucarest, la croix d'officier de l'Ordre de l'Étoile de Roumanie». Y el Duque de Amalfi, legado español, se dirigió a dicho ministro para encarecer los servicios de Basterra en los términos siguientes, significativos también para conocer su personalidad:

En casos usuales hubiera bastado a mi juicio, los merecidos elogios que he creído en el deber de tributar al señor Basterra en varios de los Despachos que llevo elevados a V.E. desde la aún cercana fecha de mi toma de posesión: pero son tantos y tan señalados los servicios que el señor Basterra ha prestado desde este puesto, que con tanto acierto ha desempeñado interinamente, al Gobierno de S.M. que cometería una gravísima omisión al no recordarlos nuevamente.

El señor Basterra ha visto, con una clarividencia que honra por igual su claro talento y su acendrado patriotismo, el porvenir económico reservado a España en Rumania y, luchando con ánimo inquebrantable y 
orden, su clasicismo mismo, hacen pensar en una reacción, favorecida por el medio intelectual en el que se movió, contra unas tendencias íntimas de signo opuesto. Sus cartas a Unamuno nos lo presentan como alguien apasionado e impulsivo, a menudo vehemente, nada equilibrado, ya mucho antes de su dolencia. Este carácter se trasluce en su estilo, cuya complejidad y ocasional retorcimiento, sobre todo en la prosa, sugieren un tormento expresivo muy lejano del clasicismo programático $^{7}$, al igual que la falta de ponderación de algunos de sus juicios y afirmaciones. Pero el interés de su figura no radica seguramente ni en su perspicacia ni en su ideología, sino en la plasmación literaria de una personalidad singular. Dentro de un grupo racionalista hasta en su vitalismo como el novecentista (al que pertenecía conscientemente como promotor de la Escuela Romana del Pirineo como sucursal bilbaína del noucentisme catalán; Ortega Gallarzagoitia 2001: 4548 ), siguió una vía media difícil, con todos los riesgos intelectuales que eso conllevaba: una lírica resecada por un exceso de ideas, por la pedagogía más o menos explícita, y una prosa de ideas en que estas, más que argumentarse, parecen expresar sobre todo hallazgos poéticos, metáforas de sí mismas.

Afortunadamente, nuestro autor supo elegir el objeto más adecuado para la índole de su talento, la Historia. Esta no es ni una ciencia exacta ni tampoco una formal, y mucho menos lo era en su época, cuando eran legión las interpretaciones del pasado que respondían a querencias perfectamente emocionales, como las que inspiraron a muchos otros filósofos de la cultura y la historia que, en casi toda Europa, se exprimieron las meninges para extraer la esencia de la nacionalidad, para lo cual se fijaban en los aspectos que más se ajustaban a sus posiciones de partida... No cabía actitud más lírica, en el fondo. Y en ese concierto de historiadores-poetas, Basterra destaca por algo más que su maestría literaria en numerosas páginas. Sus dos grandes libros de prosa adoptan una forma híbrida entre tratado y libro de viajes en primera persona que los enriquece expresivamente y exige una recepción literaria, y no filosófica, de las ideas formuladas, las cuales se presentan en un marco configurado por la experiencia del viajero, con lo que nuestro autor esquiva las trampas, en que cayeron muchos otros, del discurso demostrativo en una materia reacia a cualquier prueba racional. Por otra parte, sus observaciones

sereno, con las dificultades de orden material y orgánico, que han puesto en entredicho nuestro prestigio en este país, ha sabido levantarlo a gran altura en los círculos productores y mantenerlo con un decoro tal vez acrisolado por su excesiva modestia en los círculos sociales.

La prueba más elocuente de cuanto dejo aseverado es la simpatía que le están manifestando todos los funcionarios oficiales y en particular los del Ministerio de Negocios Extranjeros los cuales dicen, con gran sinceridad, que lamentan vivamente su partida [...].

${ }^{7}$ El de Basterra es «un castellano duro y de párrafos amplios que no huye del relativo ni de las oraciones subordinadas, y que posee una relativa exuberancia barroca, podada continuamente por la medida educación clásica del pensador» (Areán González 1953: 237). Esta retórica basterriana podía obedecer a una pervivencia de su educación finisecular, ya que «en la prosa de Basterra se detecta una cierta tendencia al recargamiento expresivo que en buena medida proviene de la vertiente más estetizante de la escritura modernista» (Nanclares Gómez 2004: 94). 
directas confieren la vividez de su personalidad a los pasajes argumentativos o puramente históricos, porque se nota una experiencia real. Estas cualidades salvan, hasta cierto punto, su ensayo de 1925 sobre Venezuela titulado Los navíos de la ilustración, pero destacan sobre todo en La obra de Trajano (1921), cuyo asunto relativamente lejano facilitó seguramente que Basterra consiguiera su libro más medido, además de original, por el tradicional desinterés de los intelectuales españoles, con la excepción novecentista, por las culturas foráneas, por una parte, y por la penuria de visiones amplias de Rumania por parte de extranjeros que conocieran profundamente su lengua, historia y costumbres, por otra. Nuestro autor se había empapado de ellas antes de escribirlo y, gracias a este conocimiento, pudo iniciar su carrera literaria con una brillantez que tal vez no volvería a igualar. Por eso, y aunque las esperanzas de Basterra de incorporar al panorama cultural español un país casi desconocido hasta entonces ${ }^{8}$ no se saldaron con completo éxito en la práctica ${ }^{9}$ y pese a que su reputación se fundó en seguida y casi exclusivamente en

${ }^{8}$ Según un amplio repertorio bibliográfico de las relaciones culturales rumano-españolas (Popa 2007), dispuesto en orden cronológico, la literatura e historia de Rumania apenas empezaron a tratarse en España a partir de 1868, cuando Andrei Vizanti, estudiante moldavo en Madrid publicó su tesina Breve noticia sobre la historia de la Rumania (Juez y Gálvez 2003). A continuación, hay que esperar a la publicación en la capital española, en 1909, del libro de viajes de un autor mencionado por Basterra en La obra de Trajano, Joaquín de la Llave y García, titulado Bulgaria y Rumania: Notas de viaje, Julio, Agosto y Septiembre de 1908, en el que se ocupa casi exclusivamente de las cuestiones militares que le interesaban, igual que en su breve volumen del año siguiente Rumania: Conferencias pronunciadas en la Real Sociedad Geográfica los dias 22 de Diciembre de 1908 y 19 de Enero de 1909; su detallada Memoria sobre el ejército rumano (Madrid, 1913) y un folleto titulado Territorios que puede reivindicar el Reino de Rumania: Noticias y observaciones comunicadas á la Junta directiva de la Real Sociedad Geográfica en la sesión del dia 8 de Febrero de 1915. Basterra, fue, pues, el que verdaderamente dio a conocer Rumania y su cultura en el mundo hispánico. El trabajo pionero de George Uscatescu señala asimismo alguna introducción académica a la lengua rumana (en concreto, la de Pedro Felipe Monlau, de 1868), pero el primer libro importante fue el de Basterra, y así lo reconoce George Uscatecu al describir el contenido de La obra de Trajano (Uscatescu 1950: 83-87), que le hace exclamar con entusiasmo: «iAdmirable viaje éste, de Ramón de Basterra, a través de la realidad rumana! En los cinco capítulos del inapreciable libro [...], encontramos, al lado de una gran curiosidad, una verdadera, auténtica pasión por el fenómeno rumano, tan lleno de interés y de sorpresas» (ibidem: 85 ).

${ }^{9}$ En la bibliografía basterriana (Larrabide 2002) no se mencionan las reseñas de La obra de Trajano en la prensa española. No obstante, aparecieron varias, si bien se trataba de meras descripciones del contenido del libro, sin entrar en juicios sobre su valor o su pertinencia, como las publicadas en los diarios El Globo y La Voz que recogemos en la bibiografía final. Por otra parte, la prensa se hizo eco de la conferencia sobre el mismo tema pronunciada en Sevilla, que se puede considerar un resumen del libro (se puede consultar al respecto Ortega 1998), puesto que, entre otros medios, en el diario nacional El Sol, órgano de los intelectuales novecentistas, apareció el 20 de mayo de 1921 una crónica muy detallada del discurso de nuestro autor, con reproducción incluso de una doină o copla rumana en su traducción basterriana. Pero el hecho de que el libro no alcanzase el eco esperaro debió de frustrar a nuestro autor, quien era tan consciente de la valía de su libro que anunció a Unamuno su proxima publicación en estos términos (Basterra 1989: 104): «Estoy en tratos con el editor para publicar mi primer libro La obra de Trajano en el que recojo un cabo suelto de historia española, 
su obra poética ${ }^{10}$, ya va siendo hora de recuperar esta dimensión rumana de su vida y obra, tan importante que cabe considerar que aquel país fue su segunda patria espiritual, hasta la misma víspera de su muerte. De hecho, fue en Rumania, en la Revista Hispánica, en la que también aparecería un extracto de La obra de Trajano (Basterra 1929), donde se publicó su último artículo, escrito seguramente en uno de sus postreros períodos de lucidez y al parecer completamente desconocido en España. La crónica, titulada «iTrajano es rumano y español!», reafirmaba las ideas que había defendido en aquel libro, aunque haciendo mayor hincapié en el desarrollo creciente de las relaciones entre los dos países, de acuerdo con el carácter paradiplomático de aquella revista bilingüe rumano-española, tan interesante como efímera (7 números), tal como sugiere la alusión final a los «intereses temporales» (Basterra 1928: 8):

Puesto que la presente reincorporación nacional de Rumania, casi en los mismos límites que le dio Trajano, demuestra que su obra está viva, están pidiendo los tiempos nuevos de la post-guerra la realización de otra conmemoración histórica. Las naciones no son, después de todo, sino caravanas que van a la sombra de los grandes hombres. Rumania y España pueden poner a la sombra de Trajano sus corazones fraternales, y con ellos sus intereses temporales.

De este modo, Rumanía fue para Basterra una patria real, con sus cualidades y defectos, y no la fantasmal de la Roma antigua de sus ensueños, aunque fuera ésta la que lo había puesto en camino hacia el Levante. Aun descontando lo que pudiera tener de licencia poética la descripción que hace en el prólogo de La obra de Trajano, titulado líricamente «El recuerdo de piedra», de sus paseos por los «abatidos escombros del Foro» (Basterra 1921: 10), estas caminatas no solo están en el origen de sus poemas de vasco transplantado a la Ciudad eterna, sino también de una vocación histórica insospechada hasta entonces. Esta vocación se centró en la figura de Trajano, cuya columna parece haber sido uno de los imanes monumentales al que se dirigían una y otra vez sus pasos. El monumento tenía el atractivo único de estar casi intacto, como una prueba sólida, y simbólica a la vez, de la persistencia del emperador, cuyo origen en la provincia romana de Hispania lo hacía más atractivo a sus ojos por razones de patriotismo. De hecho, y aunque la

reivindicando la fundación levantina para el andaluz. Veremos si la cosa responde a lo que la he destinado de efecto internacional y americano española, además, claro está de patriótico».

${ }^{10}$ Así lo considera en primer lugar uno de sus amigos, Joaquín de Zuazagoitia, en la necrología que le dedicó, titulada significativamente «La muerte de un poeta.- Ramón de Basterra» (El Sol, 21 de junio de 1928, p. 5). En el mismo diario se le rindió un homenaje en 1925 con ocasión de la erección de un monumento en su honor en Bilbao en el que varios escritores (Eugenio D'Ors, Juan Ramón Jiménez y Pedro Salinas, entre otros) glosaron su vida y obra, bajo el epígrafe de «A la memoria de Ramón de Basterra» (El Sol, 27 de enero de 1935, p. 2), haciendo hincapié sobre todo en su lírica, que ya entonces había dejado en la sombra al ensayista. Asimismo, el primer estudio crítico serio escrito en España sobre su obra se limita también prácticamente a su poesía (Díez Canedo 1928). 
idea misma de una nacionalidad española no parece muy verosímil en un ciudadano romano, la tendencia a considerar compatriotas a todos los que hubieran visto la luz en el mismo suelo, era una especie de lugar común, y no solo en España. Por lo tanto, la reivindicación como español de Trajano no parecía algo descabellado y Basterra declaró que su propósito era «recabar para la provincia española la figura de quien defendió los intereses de Italia» (Basterra 1921: 31) antes de los propios italianos, hasta esa coyuntura misma de la Gran Guerra en curso. Esta reivindicación tenía, además, la virtud de atrasar hasta aquel modelo el proceso de expansión colonial de la España moderna, que se caracterizó por un transplante poblacional semejante al producido en la Dacia vencida. Trajano era «el primer colonizador hispano antes de ser descubierto el Nuevo Mundo» (Basterra 1921: 32) y esta analogía, más literaria que rigurosamente histórica, fue la que despertó su curiosidad por Rumania, vista como el resultado levantino de la misma gesta que ganó para la latinidad el extremo occidente americano. Esta tierra era casi ignota para los españoles y Basterra solicitó su traslado a ella para redescubrirla a sus compatriotas, siguiendo la señal del Trajano de piedra: «La sombra de su columna me trazó en el suelo, como un índice el camino del viaje», tal como reza la última frase del prólogo, en el estilo poético y elevado que caracteriza el libro. Propósito idealista, pues, entreverado de actitud literaria ante la vida, a la que no dudó en sacrificar las comodidades de la Roma moderna.

Aunque España, como país plenamente neutral, mantenía relaciones con ambos bandos contendientes y sus representaciones diplomáticas continuaron su labor con la máxima normalidad posible en esas circunstancias, había sin duda destinos menos fáciles que otros, y el de Rumania se contaba entre los más difíciles. Cuando se produjo la comunicación diplomática del nombramiento de Basterra como secretario de tercera clase en la Legación Real española ante el Reino de Rumania, el 29 de marzo de 1918, el país había sido ocupado. La Revolución Rusa y la firma del Tratado de Brest-Litovsk habían dejado al país solo ante el poderío militar germánico, por lo que se vio obligado a firmar un armisticio en diciembre de 1917, a consecuencia del cual se reconocía la ocupación del sur del país, incluida la capital, mientras que las instituciones del Estado debían permanecer en Yasi (según la grafía basterriana, Iaşi en rumano), prácticamente bajo el control de los vencedores y en unas circunstancias materiales muy difíciles, pese a la satisfacción del reconocimiento de la unión de Besarabia con el Antiguo Reino ${ }^{11}$, tras el derrumbe (parcial) del imperio ruso. Basterra se incorporó a la legación tras un viaje complicado a través de las potencias ocupantes hasta Bucarest, donde le chocó la búsqueda de diversión de sus habitantes y su aceptación de buen grado, en apariencia, de la presencia militar alemana, lo que no debió de ser ajeno a la pobre

${ }^{11}$ Así se suele denominar a la Rumania independiente en su período monárquico hasta 1918 , cuando estaba constituida únicamente por los dos principados danubianos históricos de Moldavia y Valaquia y la región litoral de Dobrucha. 
visión que mantuvo sobre la rectitud moral de los habitantes de aquella ciudad ${ }^{12}$. Sin embargo, no paró mucho ella, apenas lo suficiente para poder luego ofrecer un panorama muy vívido de la capital ocupada. A finales de abril, se le aprobó el viático para su viaje a Yasi desde Bucarest, por razón del traslado obligado de capital, y tomó posesión de su cargo en la vieja ciudad moldava el 1 de junio de 1918, donde permaneció unos meses. Ese período fue especialmente duro, como contó asimismo en el primer capítulo, autobiográfico, de La obra de Trajano. Tras estos meses de penalidades, el regreso del Estado a Bucarest, tras la firma del Tratado de su nombre, dio una tregua a su salud, quebrantada por las carencias sufridas. Según su expediente personal del Ministerio español de Exteriores, el 20 de octubre de 1918 pudo tomar posesión en dicha ciudad, justo cuando se habían vuelto las tornas en contra de los Imperios Centrales. El 10 de noviembre de 1918, Rumania volvió a entrar en guerra al lado de los aliados, a tiempo para recoger los frutos de la victoria y convertirse en el país más ganancioso gracias a la aplicación en su favor del principio de las nacionalidades, por el que se reconoció la voluntad de unirse al núcleo independiente rumano de la población de esta etnia de Besarabia, por una parte, y de los territorios del Imperio Austrohúngaro en que era mayoritaria, aun englobando enclaves numerosos de alemanes y magiares en esta última región. La Gran Rumania quedó así asegurada como Estado común para la inmensa mayoría de los rumanos. Esta perspectiva significaba, para nuestro autor, la resurrección casi milagrosa de la obra de Trajano. Tras casi dos mil años de desastres, «el mapa de la antigua Dacia trajana coincidía con el de la Rumania unida» (Basterra 1921: 82). De esta manera, el viaje romántico desde el Foro del emperador en Roma le había permitido asistir a unos acontecimientos inimaginables al decidir iniciarlo, unos eventos de los que había tenido la suerte de ser testigo y que parecían confirmar el acierto de su intuición histórica, de su confianza en la vitalidad y valores latinos, que la victoria de Francia, Italia y la misma Rumania parecían reivindicar frente a la impresión tópica de decadencia en aquel contexto en que los intereses estatales se cubrían con la exaltación de la raza propia. Por eso, no extrañará que sus juicios sobre la culminación nacional rumana estuvieran tan influidos por esta particular visión suya, que determinó no solo la escritura de su libro, sino incluso su propia labor diplomática, si nos atenemos a los despachos diplomáticos que envió a sus superiores, cuyo tenor imponía prestar la atención necesaria a las condiciones reales del país.

Los informes de la legación española en Bucarest corrían a cargo personalmente del Ministro Plenipotenciario, de manera que Basterra solo debió escribirlos cuando tuvo que asumir esta responsabilidad, en calidad de Encargado de Negocios, por la ausencia del embajador, cosa que ocurrió dos veces durante su estancia en Rumania, la primera entre enero y junio de 1919, y la segunda, entre febrero y

\footnotetext{
${ }^{12}$ Para más detalles sobre la visión basterriana de la capital de Rumania, véase Mejía Ruiz 2009.
} 
mayo del año siguiente. En ellos, procedió a unos análisis objetivos de la situación rumana, examinando desde la perspectiva de un amante de la (auto)disciplina las tendencias democratizadoras tras la Gran Guerra y la expansión ideológica soviética, la reforma agraria (que vio con desconfianza al principio, antes de convencerse de que tal reforma creaba una nueva clase de propietarios que prevendría cualquier agitación revolucionaria al estilo ruso), los problemas de la reconstrucción agravados por una administración defectuosa o el juego de nuevas fuerzas parlamentarias a raíz de la aprobación del sufragio universal y el auge consecuente de los partidos con vocación de masas y, en especial, de los movimientos agraristas ${ }^{13}$. Entre esos despachos destaca el de 10 de febrero de 1919, titulado «Sobre el presente estado de este país», en que se traslucen sus ideas sobre la política y su peculiar obsesión sobre Trajano. Según nuestra autor, recién acabada la Gran Guerra, pero sin haber quedado fijadas las fronteras por los tratados de paz y con una potente ola revolucionaria en puertas, Rumania vivía momentos de incertidumbre. La economía estaba arruinada por las destrucciones de la guerra y la incompetencia administrativa no ayudaba a paliar la miseria imperante, porque «el tradicional desarreglo de la administración, la incuria en el cumplimiento del deber campean como antes de la guerra». Frente a estos vicios, la mayor esperanza la representarían los pueblos acostumbrados al mejor gobierno austrohúngaro que habían pasado

${ }^{13}$ Transcribimos a continuación algunos pasajes de estos despachos por su interés documental y por la claridad con que se manifiestan las ideas políticas de nuestro autor, a saber.

Despacho de 17 de marzo de 1920:

[...] el avance de los tiempos se va a realizar en Rumania por acometidas impulsivas, sin freno de prudencia. En su provenir inmediato será esta nación una democracia radicalísima. La desorganización que amenaza a la nación en cumplimiento de muy hermosos principios, estriba en la impreparación de sus hombres nuevos. Nunca como ahora se ve en el Parlamento que la misión de conducir a sus conciudadanos es una disciplina, adquirida en el aprendizaje de un oficio. Por ninguna parte asoma aquí esperanza de una actividad fecunda. [...] De todos estos empujes de la nueva vida, lo que se echa de menos, es un serio apercibimiento al deber, a la rectitud y al esfuerzo cotidiano, aquejando como aquejan a la población de las ciudades y al elemento burocrático todos los males de la corrupción y la holganza.

Despacho de 31 de marzo de 1920:

Nada tan cierto como que la vida en este país estará regulada en un porvenir cercano por normas políticas democráticas que contarán entre las más avanzadas de Europa; esto se puede dar por descontado; los antiguos boyardos han perdido el impulso de defensa de clase, comprendiendo las nuevas necesidades que los tiempos entrañan, pero de eso a creer que las palabras demagógicas que comienza a lanzar la Federación de la democracia nacional-social, prendan inmediatamente en las masas, ocasionando riesgos de convulsiones sociales, hay considerable distancia.

Impetuosamente comienzan, es cierto, a brotar las nuevas fuerzas democráticas, quienes piden libertades, que tan caras fueron para el siglo XIX [...]. Pero como la ley agraria de repartición de tierras, que en Besarabia es ya una realidad y pronto se aplicará al resto de la Rumania nueva, ensancha el número de propietarios rurales, estos dueños no harán sino engrasar el sentimiento de la conservación y por tanto servir a la causa del orden. [...]

Una profunda desgracia aqueja a Rumania, que tanta suerte tuvo al término de la guerra como para poder realizar la unión de toda su raza en un solo Estado, y es la división personalista entre aquellos que conducen los públicos destinos a punto tal que se olvidan de los intereses nacionales por satisfacer venganzas y pretendidos agravios de sus contendientes. Este es un gravísimo mal que, unido al desconcierto que hasta ahora ha imperado en la cosa pública, puede ofrecer el flanco descubierto a un ataque de las aspiraciones enemigas. 
a formar parte de la Gran Rumania, si no fuera porque los rumanos de Transilvania no accedían por lo general a puestos de responsabilidad. Por esta razón, el centro de la nación seguiría en manos del «elemento directivo del viejo reino», si bien nuestro autor describe con detalle cómo la participación y el triunfo en la guerra, que tanto había agrandado el país, se tradujo en una apertura considerable. Hasta los conservadores aceptaron ideas que antes hubieran parecido extremistas, como el sufragio universal, el reconocimiento de más derechos a los trabajadores y, sobre todo, una reforma agraria muy amplia, iniciada en los territorios antes pertenecientes a Rusia, pero que el Parlamento rumano hizo extensiva a todo el país, acabando prácticamente y de forma legal y pacífica con el latifundismo que tantos problemas sociales seguía suscitando en otros países, como España. Si a esto se suma que el sufragio universal se aprobó casi al mismo tiempo, y que surgieron casi inmediatamente partidos orientados hacia las masas como el agrarista Partido Nacional Campesino, además de varios movimientos socialistas marginales debido al escaso número de proletarios, era natural que Basterra afirmase que la nueva vida en el país se iba a asentar «en bases de radical democracia», una democracia que sería «opulenta» una vez superadas las agitaciones de la posguerra y de existir una dirección competente, de acuerdo con sus ideales sobre las minorías rectoras. Y entonces, Rumania estaría llamada a «renovar el apelativo que le dieron los romanos de Dacia feliz»:

En tal probable supuesto, su unificación redobla su importancia e interés que pudiera ofrecer a nuestra Patria, que es, por América, Metrópoli de una gran parte de la raza latina, a la que Rumania se siente ligada, en su origen con la fundación de nuestro Emperador andaluz Trajano, y en lo venidero, por su desenvolvimiento [de] la civilización, como la cuarta raza latina que es, establecida en el suelo de Europa.

La risueña perspectiva de una nueva potencia que reconocía su parentesco con la nación a la que servía Basterra se reafirma en otro despacho suyo poco posterior (22 de mayo de 1919), que tituló significativamente «Sobre las espontáneas simpatías de este país por España». Su manifestación era más bien simbólica, tal como la preferencia dada al representante español en una ceremonia con todo el cuerpo diplomático. Al parecer, el Presidente del Consejo de Ministros, Ionel Brătianu, justificó su gesto «afirmando que la constitución de la unidad rumana era en parte una fiesta española pues que, al cabo de los siglos, perseveraba y se cumplía la obra inmortal fundada por el hijo de España, Trajano», lo que sugiere que la interpretación basterriana del destino de Rumania no era solo personal, sino que la compartían, al menos en sus muestras de gentileza diplomática, las élites del país, especialmente las representadas por el Partido Nacional Liberal entonces gobernante, cuyo occidentalismo constituía uno de los puntos más sólidos de su ideario. La latinidad de Rumania era, para los occidentalistas, un argumento que fundaba el carácter plenamente europeo del país, tanto frente al extranjero, como frente a la 
propia opinión pública rumana, a la que ya cortejaba por entonces un nacionalismo particularista que hacía hincapié, precisamente, en lo distintivo respecto a la historia y tradiciones occidentales, aunque en 1919 la situación no estaba todavía clara y la tradicional cercanía de los liberales rumanos a Francia e Italia había recibido un espaldarazo por el papel fundamental de estos aliados en el desenlace feliz de la Gran Guerra para Rumania. En este contexto, Basterra procuró que España aprovechara la ocasión para sumar también su influencia, que se debía traducir en mayores relaciones comerciales y en contactos culturales más estrechos ${ }^{14}$ :

Hállase esta infortunada raza rumana que se ha salvado por milagrosa tenacidad, necesitada de los prestigios de la tradición y de relacionarse conforme a su origen histórico que le hace considerarse como un fragmento de occidente arrojado a los confines orientales, y de nuestra parte no es de desdeñar esta espontánea simpatía que se nos brinda, a la par que conduelen conspicuas personalidades rumanas de que nuestra presencia aquí no sea más activa. No deja de haber cierto fondo de afecto en la extrañeza que me han testimoniado aquí repetidas veces, harto justificada, por desgracia, y producida por la inacción de que da pruebas nuestro pueblo, cuando por el pasado, entre todos los países de origen románico, es el nuestro el más señalado por su esfuerzo, objeción a la que no sé responder si no por alusiones a lo venidero, señalando que dentro de imprecisas, por ahora, formas de unión existimos ochenta millones de españoles de raza en el mundo.

Pese a la buena disposición del Ministerio de Estado español ${ }^{15}$, no parece que la cosa pasara de las buenas intenciones, a juzgar por un despacho de Basterra fechado el 5 de febrero de 1920. En el mismo se describe con todo detalle la ceremonia de creación de la universidad rumana de Cluj, en la que nuestro autor participó como representante de España pronunciando un discurso en rumano ${ }^{16}$, cuya

${ }^{14}$ Basterra propone, por ejemplo, la colaboración de las academias de la lengua española y rumana, tal como indica en este mismo despacho:

Esperando sus órdenes para poder emprender el camino de acción que tales simpatías señalan, elevo a su superior atención lo pertinente que sería, caso de que V.E. estime oportuno cultivar estos gérmenes, el que nuestra Real Academia de la Lengua, depositaria de las espiritualidades nacionales, pagara algún acto de cortesía, como los que acostumbra con los países españoles de América, procediendo a una remisión de sus publicaciones a la Academia Romana [sic!] de Bucarest, que lo agradecería con reconocimiento efusivo. Tengo entendido que desea la dicha entidad invitar, con la preferencia que da Rumania entre los pueblos latinos a España, por la deuda de gratitud de su fundación hispánica, a un miembro de nuestra real Academia para que asista a alguna de las ceremonias solemnes con que se conmemora el cumplimiento de la obra de Trajano realizada en 1919, tras de siglos de desventuras en que la raza rumana estuvo separada.

No nos consta que se produjera tal intercambio.

${ }^{15}$ Tal como se deduce del testimonio de Basterra también en este documento:

En cumplimiento de las órdenes de V.E. incluidas en telegrama circular que hace relación a la orientación patria en política internacional, hice partícipe, confidencialmente, de las decisiones de V.E. al Subsecretario de Negocios Extranjeros, quien al conocerlas tuvo para España expresiones de estima haciendo votos por que los lazos que la Historia y la común herencia románica entre nuestros países, se estrechen más en lo venidero.

${ }^{16}$ En el archivo del Ministerio de Estado se conserva el número de L'Indépendence roumaine dedicado a la ceremonia, que prueba la veracidad del propio testimonio de Basterra en su despacho, a 
traducción francesa (la única conservada) reeditamos aquí, y cuyo tenor se aparta mucho de los discursos convencionalmente diplomáticos de los demás representantes, ya que abunda en la idea tan reiterada por él del vínculo que une Rumania a España en la persona de Trajano. Pero, aparte de las expresiones de afecto y de las flores del estilo, «estos alejados recuerdos, a los que, no obstante, son particularmente sensibles los rumanos» no se habían traducido en una intensificación de las relaciones comerciales y «el mercado rumano, que es unos de los más ricos emporios naturales del continente» seguía siendo tierra incógnita para los españoles. Los lazos culturales no facilitan necesariamente el comercio y, si Basterra hizo tanto hincapié en los primeros, sería para convencer a sus superiores de unas potencialidades inexplotadas, al tiempo que se hacía un favor a sí mismo al intentar seguramente que sus concepciones particulares influyeran en la política oficial de su Ministerio. Pero no eran tan ingenuo como para que ello lo cegase ante la realidad. En el despacho siguiente, de 14 de febrero de 1920, repasa los intereses extranjeros de la Gran Rumania y señala que se limitarían al «radio balcánico». La comunidad de origen con España, Francia e Italia estaba bien para ceremonias como la de Cluj y para expansiones retóricas en la prensa, pero se trataba de un «impulso académico, poco consistente todavía», al igual que la simpatía por la patria de Basterra:

El que España, en la atención rumana se haya adelantado estos días a las grandes potencias no latinas, protectrices [sic!] de Rumania, no es prueba sino de que existe, un confuso, irreal e informe, un ideal latente al que no faltará el asentimiento cordial de la masa, aunque, por el momento, no parece estar llamado sino a ejercitar una influencia meramente sentimental e ilusoria.

En efecto, la evolución de la Gran Rumania siguió el camino opuesto, en el sentido de un acercamiento creciente a Alemania, de la que pasó a depender política y económicamente, hasta punto de tener que aliarse con ella en esta contienda

saber: «como se me concediese el honor de otorgárseme la palabra, me dirigí a Sus Majestades y a la asistencia en lengua rumana». El gesto de dirigirse a la concurrencia en su idioma, y no en francés, que era la lengua diplomática y la preferida por las clases acomodadas de Rumania debió de ser el principal motivo del entusiasmo con que fue recibida la intervención de Basterra, con vitoreos a España incluidos, tal como da a entender el cronista de L'Indépendence roumaine (1920: 2): «Ce fut aussi une agréable surprise pour tous que d'entendre le chargé d'Affaires d'Espagne s'exprimer avec facilité et avec élégance dans notre propre langue roumaine et l'assemblée ne lui ménagea pas ses applaudissements et sa gratitude bien méritée». Asimismo, el diario Universul (1920) atestigua la impresión que el dominio del rumano por Basterra produjo en el público: «Reprezentantul Spaniei Bastara [sic!] vorbeşte româneşte, stârnind aplauze furtunoase». Así pues, durante su estancia, relativamente breve, Basterra se esforzó por aprender el idioma y lo consiguió en gran medida, como sugieren estos testimonios, así como el hecho de que Nicolae Iorga lo llamase en su necrología «omul care ştia româneşte» (Iorga 1929). Basterra conocía la historia y la literatura rumanas en la lengua original, y este conocimiento era lo suficientemente raro como para que se considerara digno de mención. 
en la Segunda Guerra Mundial, cuando llegó también a su paroxismo el nacionalismo autoctonista y antioccidental, esto es, lo contrario de la solidaridad latina en la que tanto esperaba Basterra... Pero no adelantemos acontecimientos. Durante su estancia en Rumania, el feo etnicismo que se fue imponiendo poco a poco entre numerosos intelectuales rumanos no había cuajado aún, y la preeminencia ideológica en este ámbito, y en rivalidad directa con los liberales que preconizaban la sincronización total con la Europa avanzada, aun a expensas de acabar con tradiciones supuestamente venerables, aún correspondía a un intelectual de la vieja guardia, el ilustre historiador Nicolae Iorga, cuya producción ingente y de una calidad historiográfica reconocida en toda Europa se compaginaba con una labor cultural de defensa de las esencias nacionales rumanas, de su lengua y de su clase social mayoritaria, el campesinado, que lo habían convertido en profeta y símbolo de la Rumania unificada, además de su representante cultural máximo. Iorga asumía con gusto esta función y, en esta calidad, el 20 de mayo de 1919 invitó a Basterra, junto a un diplomático italiano y la Princesa Cantacuzino, a una excursión a Vălenii de Munte, su «feudo intelectual», tal como lo denominó nuestro autor en un despacho firmado dos días después y en el que se trasluce la impresión que le produjo el recibimiento hasta el punto de señalarlo como con «valor de augurio», aunque a un lector de hoy la «espontánea manifestación lugareña» que tanto lo emocionó parece haberla preparado muy bien Iorga según el gusto folclórico (y con profusión de banderas) que mejor efecto podía hacer entonces a los representantes extranjeros ${ }^{17}$. Con todo, esta excursión no se quedó en una iniciativa de propaganda diplomático-turística. Cuando Iorga habla en $O$ viață de om aşa cum a fost de su viaje a España en 1927, cuenta cómo nuestro autor le sirvió de guía en Madrid y Toledo y recuerda aquella excursión a su villa de los Cárpatos que cimentó su amistad (Iorga 1933: 158):

${ }^{17}$ Dejamos a los lectores juzgar por sí mismos:

Como detalle episódico y revelador de ese sentimiento amistoso en el pueblo rumano, estimo necesario participar a V.E. lo imprevisto de una manifestación de simpatía de que España fue objeto inopinadamente. Habiendo el 20 del corriente emprendido una excursión a Valen de Munti [sic!], en compañía del Agregado Militar de Italia, General Peano y de la Señora Princesa Cantacuseno [sic!], dirigida por el ilustre historiador rumano N. Iorga (quien participó de antemano, manteniendo el secreto de su iniciativa, la noticia de nuestra llegada), nos encontramos sorprendidos con que en la mencionada localidad nos aguardaban las Escuelas, vestidas en traje nacional, y arborando los alumnos banderas españolas e italianas, quienes apenas echamos pie a tierra, entonaron los himnos nacionales, entremezclados con aclamaciones de Viva España (Traiască Hispania) y Viva Italia, Vivan las naciones hermanas, causándome grata extrañeza el ver en muchos de los establecimientos de enseñanza la bandera española en medio de la italiana y rumana, topando con la misma perplejidad al encontrarme en la fachada de la casa en que nos hospedamos, propiedad del mencionado ilustre historiador, con las banderas de todos los países aliados y en lugar preferente la española [énfasis del autor], que producía en mí bella emoción a la que no estaba acostumbrado. El hecho de que esto ocurriera en una pequeña población que es, por decirlo así, feudo intelectual del aludido ilustre Señor Iorga, no merma importancia al hecho y recibiendo de manos de las señoritas del lugar, engalanadas con los atavíos nacionales, innumerables manojos de flores, mientras me decían: Viva España, sorprendiome de la perduración del recuerdo histórico, de la colonización trajana que aquí mantiene vivo la enseñanza. 
Am găsit aici pe un prieten din anii de după războiu, diplomatul şi poetul de origine bască Ramón de Basterra, care cercetase cu mine pietrele de pe Valea Teleajenului, care-î plăcuse aşa de mult acelui ce cîntase într-o proză ritmată, plină de frumuseți inedite, Opera lui Traian.

Su muerte le inspiró asimismo una de los textos más conmovedores de la serie de necrologías titulada Oameni cari au fost, cuyo título, «Amicul nostru Basterra» es de por sí elocuente y donde aludió también a La obra de Trajano con elogios que no se refieren esta vez al estilo, sino a la penetración rara con que había sentido a Rumania (Iorga $1929^{18}$ ):

Poet de chemare, unul dintre cei mai înzestrați scriitori ai generaţiei tinere, el a privit cu adânc interes zbuciumul nostru. Şi ne-am trezit cu o carte din acelea pe care nu le dau diplomații: Opera lui Traian, la care critica îndreptățită se uneşte cu cea mai înțelegătoare simțire a tragediei noastre [...].

Al final, recomienda que estas «rândurile de poesie închinate rasei noastre» (ibidem) se traduzcan a la lengua del país honrado con ellas, como mejor homenaje al fallecido ${ }^{19}$, a quien siguió recordando con afecto hasta muchos años después: la publicación de un fragmento de La obra de Trajano en la revista española Vértice (Basterra 1940) le inspiró un sentido artículo de recuerdo, en que parece quejarse, además, del inmerecido escaso eco del libro del amigo fallecido prematuramente (Iorga 1940):

A fost aici un necontenit cercetător al locurilor şi al oamenilor. A mers cu mine prin văile depărtate, a fost în tovorăşia oamenilor de aici parcă ar fi fost acasă la dînsul, a observat, a păstrat şi a simţit nevoia să scrie, să recunoscă şi să laude. Traian era unul dintre ai lui, Ibericii, şi, cînd, vorbia de „opera» împărătească, el o vedea ca o ispravă a rasei sale, de care lega, supt astfel de auspicii, pe a sa.

Cartea n-a fost de loc cetită, aici şi apoi uitată acolo, iar tînărul scriitor, aşa de mîndru, pe urmă, de a-mi arăta, loc de loc, patria sa, a trecut prin oboseala minții, a biruit-o, a căzut din nou şi astăzi se odihneşte.

El elogio repetido de la obra y la persona de Basterra en boca del supremo conocedor de la historia de Rumania, hace lamentar que Iorga no le dedicase un es-

${ }^{18}$ Esta breve necrología se había publicado en el diario Neamul românesc y la reprodujo el segundo número (1929) de Revista Hispánica, que es la versión que citamos.

${ }^{19}$ «Nu poate fi un omagiu mai frumos memoriei lui decât să le dăm româneşte poporului nostru» (ibidem). El proyecto de traducir el libro se barajó décadas después, si hemos de creer del campeón español de Basterra (Díaz-Plaja 1980): «Allí [en la legación española] completa su conocimiento de Rumania y toma conciencia del sentido de su historia, que cristaliza en un hermoso libro, La obra de Trajano, que está traduciendo al rumano la eminente hispanista Domnita Dumitrescu». Esta profesora emigró a los Estados Unidos y el libro se quedó en el limbo... 
tudio crítico o, al menos, no lo hemos localizado ${ }^{20}$, pero creemos que será suficiente para sugerir el valor intrínseco de la empresa basterriana en favor de la creación de vínculos culturales y de todo tipo con la Gran Rumania. Independientemente del escaso resultado práctico de sus esfuerzos, merece la pena recuperar este episodio ignorado de las relaciones entre España y aquel país mediante los textos que figuran a continuación, a la espera de la necesaria reedición española de la obra maestra en prosa del autor, La obra de Trajano.

\section{Bibliografía}

AMAT, Jordi (2004): «Guillermo Díaz-Plaja lee a Ramón Basterra (1941): Un episodio de la cultura fascista española». Ínsula: revista de letras y ciencias humanas 696: 11-17.

ANÓNIMO (1920): «Les fêtes de Cluj.- L'inauguration de l'Université.- Les discours», L'Indépendance roumaine 5/II: 1-2.

(1920): «Marile serbări culturali din Cluj». Universul 5/II: 1.

(1921): «Bibliografía.- La obra de Trajano, por Ramón de Basterra». El Globo 1/III: 2.

(1921): «Una conferencia de Ramón de Basterra en el Ateneo de Sevilla». El Pueblo Vasco 8/V: 5.

(1921): «En el Ateneo.- El primer colonizador español. Trajano y su fundación en Oriente.- Conferencia de don Ramón de Basterra». El Sol 20/V: 2.

AREÁN GonZÁLEZ, Carlos Antonio (1953): Ramón de Basterra. Madrid: Cultura Hispánica.

AYALA, Francisco (1927): «Basterra, el granviario». La Gaceta Literaria I, 21: 1. BASTERRA, Ramón de (1921): La obra de Trajano. Madrid: Calpe.

(1928): «iTrajano es rumano y español!». Revista Hispánica I, 1: 7-8.

(1929): «La obra de Trajano». Revista Hispánica II, 5: 6.

(1940): «La obra de Trajano». Vértice XXVIII, 1: 19 y 62.

${ }^{20}$ En cambio, le dedicó el primer estudio crítico en absoluto, antes incluso que en la propia España, al comentar por extenso su volumen de poesía La sencillez de los seres (1923), del que citó bastantes versos en traducción rumana propia. El motivo de esta atención hacia una obra más bien menor en la producción basterriana hay que buscarla en la sintonía estética e ideológica entre los dos escritores. Iorga era el campeón de la tendencia ruralista de exaltación de las tradiciones populares del campo, únicas verdaderamente nacionales para él, y al campesino rumano como compendio de las virtudes patriarcales correspondía el vasco cantado en los idilios de Basterra. Iorga se preguntó cómo el poeta, que procedía de un medio de alta cultura y se movía en la sociedad internacional de los círculos diplomáticos, había acabado por manifestar esta alma campesina tan inesperada. La respuesta sugerida señala una influencia de su escuela literaria, de la que Basterra representaría el equivalente español más claro. Se trataría entonces de una de las primeras influencias culturales de Rumania en España, y no extrañará, por lo tanto, que Iorga la destacara al ser él mismo el mayor promotor de esa clase de literatura (Iorga 1923: 374):

Sau, trăind la noi cei doi ani, întrînd în contact cu societatea noastră dominată de țeran, oameni muncitori şi fetele gingaşe, simțind cum aici îi bate în față aroma secolilor, şi-a întărit, pănă la nevoia de a-l rosti, sufletul lui de acasă? 
(1970): Papeles inéditos y dispersos de Ramón de Basterra, Guillermo Díaz Plaja (ed.). Madrid: Ministerio de Asuntos Exteriores.

(1989): Cartas a Miguel de Unamuno, J. I. Tellaechea (ed.). Bilbao: Caja de Ahorros Vizcaína.

DíAZ-PLAJA, Guillermo (1941): La poesía y el pensamiento de Ramón de Basterra. Barcelona: Juventud.

(1980): «La obra de Trajano». $A B C$ 11/XII: 3.

DíEZ CANEDO, Enrique (1928): «La obra poética de Ramón de Basterra». El Sol 30/VIII: 5.

DuPlÁ, Antonio (1996): «El clasicismo en el País Vasco: Ramón de Basterra». Vasconia 24: 81-100.

IORGA, Nicolae (1923): «Un poet Hispano-Basc». Ramuri XVII: 369-374. (1929): «Amicul nostru Basterra». Revista Hispánica 2: 18. (1932): Memorii. Însemnări zilnice. Bucureşti: Editura Naţională.

(1936): "Amicul nostru Basterra», in Oameni cari au fost, tomo III, pp. 259-260. Bucureşti: Fundaţia pentru Literatura şi Arta „Regele Carol”. (1940): «Un vechi şi rar prieten». Neamul Românesc 27/III: 1.

JIMÉNEZ Juan Ramón (1960): «Ramón de Basterra», in Españoles de tres mundos, Ricardo Gullón (ed.), pp. 190-193. Madrid: Afrodisio Aguado.

JUEZ GÁlVEZ, Francisco Javier (2003): «El primer alumno rumano de la Central (1865-1868): “Acercando así la Romanía á la civilización de las demás naciones latinas"». Revista de Filología Románica 20: 123-134.

LARRABIDE, Aitor L. (2002): «Bibliografía de Ramón de Basterra». Letras de Deusto XXXII, 94: 141-174.

MAINER, José Carlos (2001): «Para leer a Ramón de Basterra (instrucciones de uso)», in Ramón de Basterra, Poesía, tomo I, pp. XIII-LVII. Madrid: Fundación BSCH.

(2003): «Las señas de Vírulo (1924-1927), héroe de Ramón de Basterra (con unas notas sobre la tercera parte inédita)», in Poesía lírica y progreso tecnológico (1868-1939), Sabine Schmitz y José Luis Bernal y Salgado (eds.), pp. 163-193. Madrid - Frankfurt am Main: Iberoamericana - Vervuert.

MEJÍA RUIZ, Carmen (2009): «El Bucarest de Ramón de Basterra entre oriente y occidente», in Bucarest: luces y sombras, Diego Muñoz Carrobles y Juan José Ortega Román (eds.), pp. 63-80. Sevilla: Grupo Nacional Editores.

NANCLARES GóMEZ, Gustavo (2004): «Modernismo y subjetividad en la prosa ensayística de Ramón de Basterra». Sancho el Sabio: Revista de cultura e investigación vasca 20: 87-100.

Ortega Gallarzagoitia, Elene (1998): «Ramón de Basterra en Sevilla». Ámbitos: Revista internacional de comunicación 1: 333-344.

(2001): El prófugo de la melancolía, la poesía de Ramón de Basterra. Bilbao: Ayuntamiento de Bilbao - Área de Cultura y Turismo. 
POPA, Mircea (2007): Relații culturale şi literarare româno-spaniole de-a lungul timpului (53-2007). Bibliografie cronologică selectivă. Alba Iulia: Aeternitas.

THEODORESCU, Barbu (1976): Nicolae Iorga (1871-1940). Biobibliografie. Bucureşti: Editura Enciclopedică Română \& Editura Militară.

USCATESCU, George (1950): Relaciones culturales hispano-rumanas. Madrid: Centro de Estudios Orientales.

VIDAL, Fabián (1921): «Hombres y tierras: La obra de Trajano». La Voz 15/III: 1. 


\section{Textos $^{21}$}

Discurso de Basterra pronunciado el 2 de febrero de 1920 con ocasión de la inauguración de la Universidad rumana de Cluj y publicado en traducción francesa en el diario L'Indépendance roumaine el cinco de febrero de 1920 (página 2):

M. de Basterra, Chargé d'affaires d'Espagne prononce, en langue roumaine, le discours qui suit:

«Majesté, Madame, Altesses Royales, M. le Recteur, Mesdames et Messieurs,

La Légation royale d'Espagne, invitée par le gouvernement de S.M. le Roi de Roumanie à assister à l'inauguration de l'Université de Cluj, a le grand honneur d'être l'interprète des sentiments d'amitié du pays dans lequel le fondateur de votre Nation, l'Empereur Trajan, a vu le jour.

Dans le monde, deux pays peuvent avec force revendiquer [sic] la glorieuse personnalité de Trajan: l'Espagne, située au Soleil Couchant, qui le vit naître, et la Dacie, l'œuvre du grand Trajan, vers laquelle sa vie durant allèrent toutes ses pensées, pays vers lequel le Soleil se lève. Trajan est vôtre tout autant qu'il est nôtre. Aujourd'hui encore son bras puissant nous unit.

Dans tout le cours des temps, ma patrie a conservé vivante [sic] le souvenir de notre grand Trajan, le conquérant de Dacie qui, de retour à Rome, patrie de notre communauté spirituelle, afin de fêter son triomphe, suspendit son entrée dans la Ville jusqu'à ce que sa mère arrivât d'Espagne. La vieille mère de $[\mathrm{sic}]$ puissant empereur entra dans la Ville Éternelle comme une Impératrice, à la droite de son "divin" fils et prit part à ses côtés aux fêtes de la Victoire. Par elle, l'Espagne a assisté à votre naissance.

Pendant de longs siècles d'adversité, en Occident, nous avions perdu votre trace. Rarement, très rarement, des nouvelles de vous nous parvenaient encore du lointain Orient. Mais quelle merveilleuse vitalité que celle de votre race! Il est bien vrai, le proverbe roumain qui dit que: "Le Roumain ne périt pas!" Il a été donné à notre génération de voir se réaliser à nouveau l'œuvre du grand Trajan: "La Roumanie unifiée, Dacia rediviva!"

En passant par les si belles et si fertiles plaines de Transylvanie, j'ai senti plus que jamais qu'elles conservent plus admirablement peut-être et plus profondément l'héritage de Rome. L'inauguration de cette université prouve une fois de plus que votre race, qui a produit une des plus belles civilisations populaires du monde entier, race que seuls les malheurs des siècles passés ont empêché d'exprimer toute son âme comme ont pu le faire d'autres peuples plus heureux, ne tardera pas à ajouter désormais aux voix d'Alexandri et d'Eminesco [sic] l'expression complète de toute sa pensée.

Et voici qu'au milieu de votre sombre destinée l'heure de la joie est venue. Plusieurs nations en Europe s'unissent à vous à cette heure par la pensée et fêtent avec vous le moment de votre réveil national. Et n'oubliez pas non plus que grâce à d'autres Trajans, à ces conquérants appartenant à ma nation, qui traversant les Océans, ont découvert et colonisé

${ }^{21}$ El texto sigue fielmente las fuentes originales, aunque hemos modernizado la ortografía y corregido varias erratas del artículo en lengua española, mientras que hemos transcrito sin cambios la traducción francesa, bastante defectuosa, del discurso pronunciado por el autor en rumano, que no hemos podido localizar, si es que se conserva. 
l'Amérique et donnèrent jadis à l'Espagne un monde nouveau, ce monde qui est l'Amérique latine conserve aujourd'hui encore l'héritage classique de l'antique Rome.

Ces millions et ces millions d'hommes, toute cette Humanité, fils de notre vieille mère Rome, fêtent en ce jour les plus jeunes d'entr'eux, la race roumaine, la dernière venue parmi eux, mais qui voit cependant aujourd'hui l'heureuse réalisation de son Idéal national!

Vivent les glorieux Souverains de la Grande Roumanie!

Vive l'Université de Cluj!

Vive la Grande Roumanie!»

(Les belles paroles si opportunes de chaleureuse affection et de solidarité latine prononcées au nom de l'Espagne, cette sœur lointaine mais non moins chère à laquelle nous unissent étroitement les liens de l'origine commune et dont la Dynastie est apparentée de près à la nôtre, provoquèrent parmi toute l'assistance un enthousiasme sans pareil. Ce fut aussi une agréable surprise pour tous que d'entendre le chargé d'Affaires d'Espagne s'exprimer avec facilité et avec élégance dans notre propre langue roumaine et l'assemblée ne lui ménagea pas ses applaudissements et sa gratitude bien méritée). 
Artículo publicado en Revista Hispánica, de Bucarest, en diciembre de 1928.

\section{«iTRAJANO ES RUMANO Y ESPAÑOL!}

Son algunos los españoles a quienes atrae el destino de Rumania, país fundado por un compatriota, ya que Trajano es español.

La ecuación Oriente-Occidente, que empieza a sugestionar a tantas mentes continentales, es la dualidad que constituye el destino rumano. Rumania es el pueblo cuyo hado fluye entre ambas riveras. Por razón del suelo Rumania es Oriente; por razón del origen civilizador, Occidente. Si su Danubio desemboca en Asia, Trajano la remonta a Europa. Trajano la remonta al extremo Occidente, a España que es la finis terrae de los antiguos.

En efecto, son algunos los españoles a quienes preocupa el interesante momento que actualmente vive Rumania. El pensamiento de la unidad de su raza ha sido coronado por un esfuerzo afortunado. Ábrese entre Rumania el nuevo ciclo de su unidad lograda. Para la actividad espiritual del bello país hay todo un programa de amistosas relaciones con otros pueblos afines. Diplomáticos, conferenciantes y publicistas rumanos han abierto camino fecundo de mutua comprensión con Francia e Italia, las hermanas latinas. Pero los dos países hermanos en latinidad, del extremo Oriente y el extremo Occidente, Rumania y España, apenas acaban de iniciar, en gran estilo, sus relaciones de generoso trato.

Dos distinguidos Representantes diplomáticos, el Príncipe Bibesco, en Madrid, y el brillante Ministro de S. M. Don Francisco de Cárdenas, en Bucarest, son actualmente los adelantados de esta cruzada de simpatía. Hasta los niños más jóvenes del país que representa brillantemente el Príncipe Bibesco, en la Corte de España, aprenden en las escuelas de los Cárpatos que Trajano fue español. En todas las aulas del pueblo que tan acertadamente representa Don Francisco de Cárdenas, se recita que era del sur de la península occidental el Emperador Trajano. Pero este hecho, capaz de ser una cadena de afecto que una los corazones rumanos y españoles, no pasa por el momento de ocupar una línea de texto. Esta línea de texto es sin embargo el evangélico grano de mostaza. A poco riego de cordialidad que le den los Gobiernos, los diplomáticos, los escritores, los periodistas, crecerá y se hará un árbol frondoso de ramas, en cuyo ramaje se aposarán las aves del nuevo espíritu.

Por su hado histórico (cada pueblo, como cada ser, tiene el propio), España es un terreno feraz para estas conmemoraciones históricas. Es conocido en la historia del planeta que España es fundadora de 19 naciones. Atravesando el mar Atlántico, la discípula de Roma que es España, en esta obra egregia de civilización que consiste en abrir los ojos a los dormidos en la prehistoria, España es la creadora de la Argentina, de Méjico, de Perú, de Chile y de tantos países más de América y de Oceanía. Hernán Cortés, español, es el Trajano de Méjico. Pizarro es el Trajano de Chile. Fiestas, veladas y actos públicos conmemoran en España el recuerdo de esas figuras históricas y la amistad, a su sombra, entre los pueblos.

Puesto que la presente reincorporación nacional de Rumania, casi en los mismos límites que le dio Trajano, demuestra que su obra está viva, están pidiendo los tiempos nuevos de la post-guerra la realización de otra conmemoración histórica. Las naciones no son, después de todo, sino caravanas que van a la sombra de los grandes hombres. Rumania y España pueden poner a la sombra de Trajano sus corazones fraternales, y con ellos sus intereses temporales.» 